\title{
ENVIRONMENTALLY FRIENDLY COASTAL PROTECTION BASED ON VERTICAL DRAINS
}

\author{
Poul Jakobsen and Claus Brøgger ${ }^{2}$
}

\begin{abstract}
A Field test over $11 \mathrm{~km}$ with the SIC vertical drain system was carried out in January 2005 up till January 2008 and placed at Skodbjerge at the Danish west coast. Already after 6 month has the vertical drain system stabilized the beach in an equilibrium profile. The average beach level from the dune foot and $100 \mathrm{~m}$. wide was after 3 years up to 157 $\mathrm{cm}$ higher in the drained areas in relation to the reference area 2 . The erosion was stopped in the drained area's, and the sand drift increased to the dune system over the next 3 years. The sand drift from the beach to the dune system is calculated to $69-76$ cubic meters pr. meter along the coastline in the drained areas over 3 years.
\end{abstract}

\section{Introduction.}

In accordance with the agreement of 10 Juni 2004 between Skagen Innovation Center (SIC) and the Ministry of Transport a field test with purpose of demonstrating the efficiency of the SIC vertical drain system as a mean for coastal protection was initiated in a meeting 24 August 2004. The project is started up in January 2005.

The test period is three years. The first evaluation report was agreed to be made after the first 6 month. Afterwards are the results evaluated yearly and finally after 3 years.

It was agreed with the Ministry of Transport that the effect of the SIC system should be compared to conventional coastal protection methods.

The Danish west coast is a high erosion area as we see in fig 1 . The erosion at $110 \mathrm{~km}$ is total 4.030 .000 cubic meters yearly.

This coastline is nourished with 2,5mill. cubic meters sand yearly over the last 25 years. The net result of the sand nourishment over 25 years is negative with -38.250 .000 cubic meters and the efficiency is negative with $160 \%$ yearly after an investment of 2.0 billions DKK equal to 270 mill. Euros. This is the background for the interest from the Ministry of Transport to support development of new effective and environmentally friendly coastal protection methods.

Field and laboratory observations have shown, that a relatively low beach ground water table enhances beach accretion, while a high water table promotes erosion (L. Li and D.A. Barry)

The test site is placed by Skodbjerge at the Danish West Coast

\footnotetext{
${ }^{1}$ Skagen Innovation Center, Dr. Alexandrinesvej 75, 9990 Skagen Denmark

${ }^{2}$ Skagen Innovation Center, Dr. Alexandrinesvej 75, 9990 Skagen Denmark
} 


\section{Test Site}

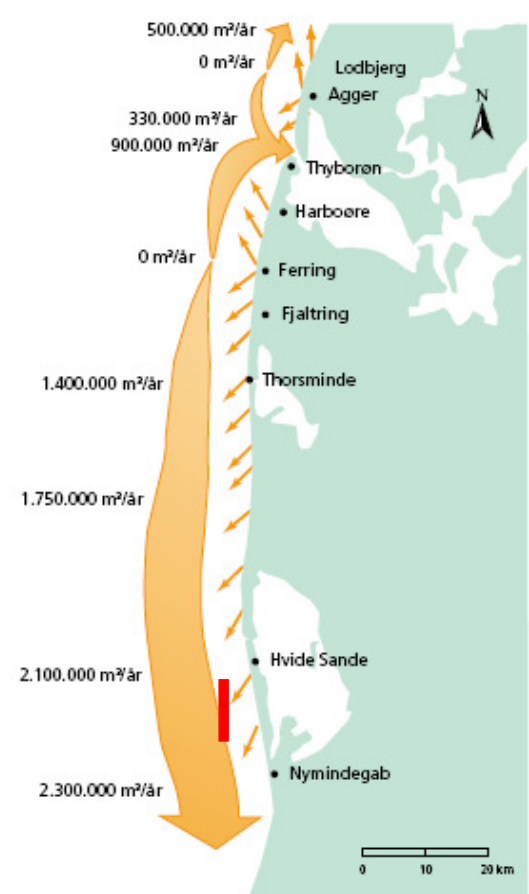

Fig. 1

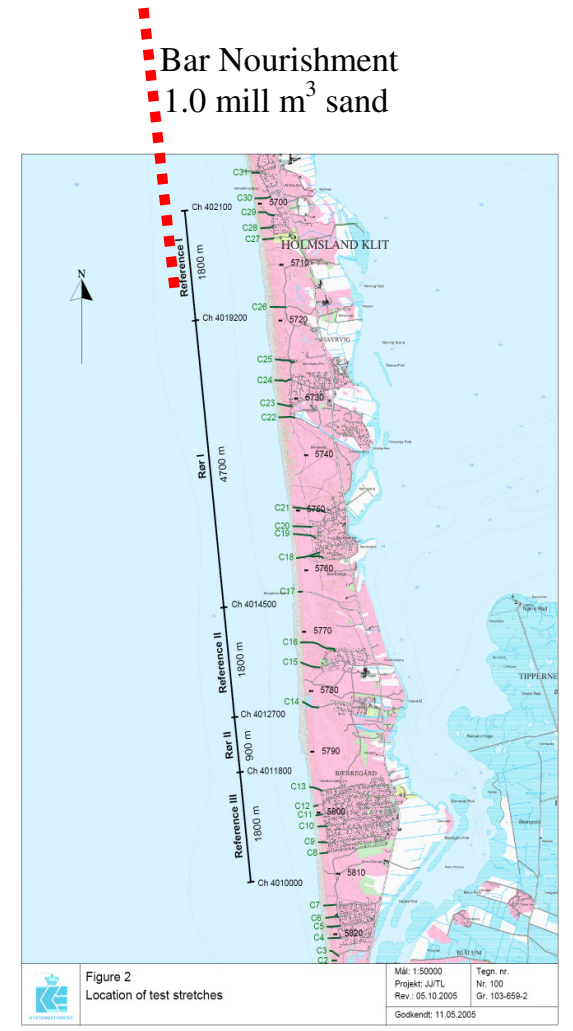

Fig. 2

The test site is placed $5 \mathrm{~km}$ south of Hvide Sande Port in a lee side erosion area. The Coastal Authority has tried to disturb the project with an unplanned Bar nourishment at 1,0 mill. $\mathrm{m}^{3}$ sand, but the sand is still lying in the area, where the sand was placed. There is a well known competition situation between SIC and KDI. $190.000 \mathrm{~m}^{3}$ sand are placed off shore in ref. 1.

The test area is spitted up in the following areas.

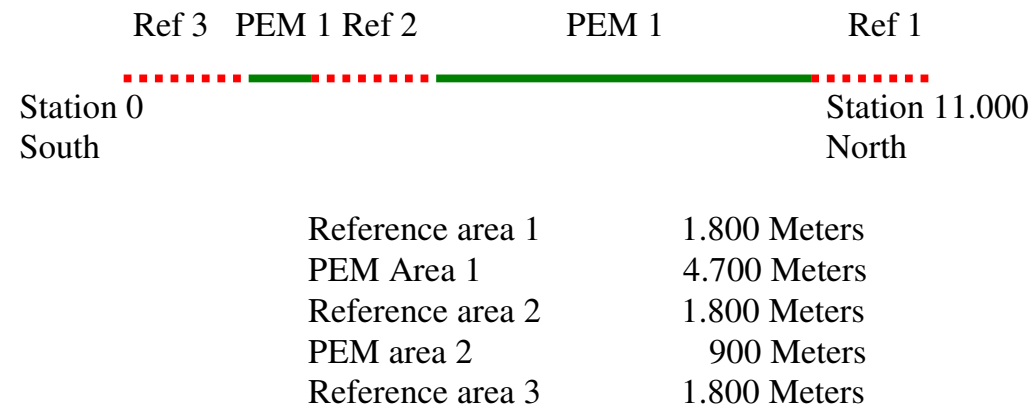




\section{Hvide Sande Port}

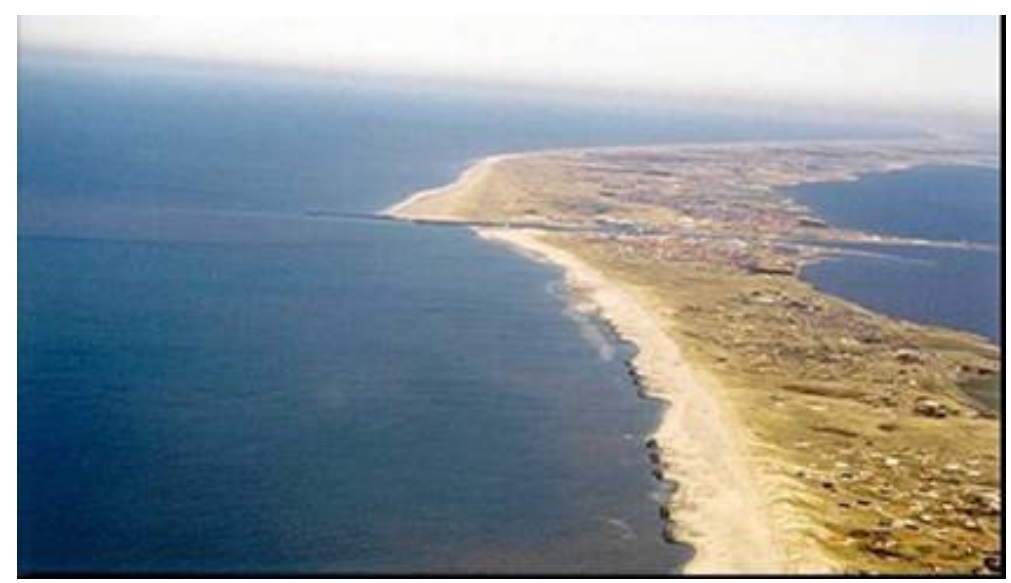

Fig. 3

A groin of rocks is placed 450 meters out in the sea north of the channel into Hvide Sande Port.

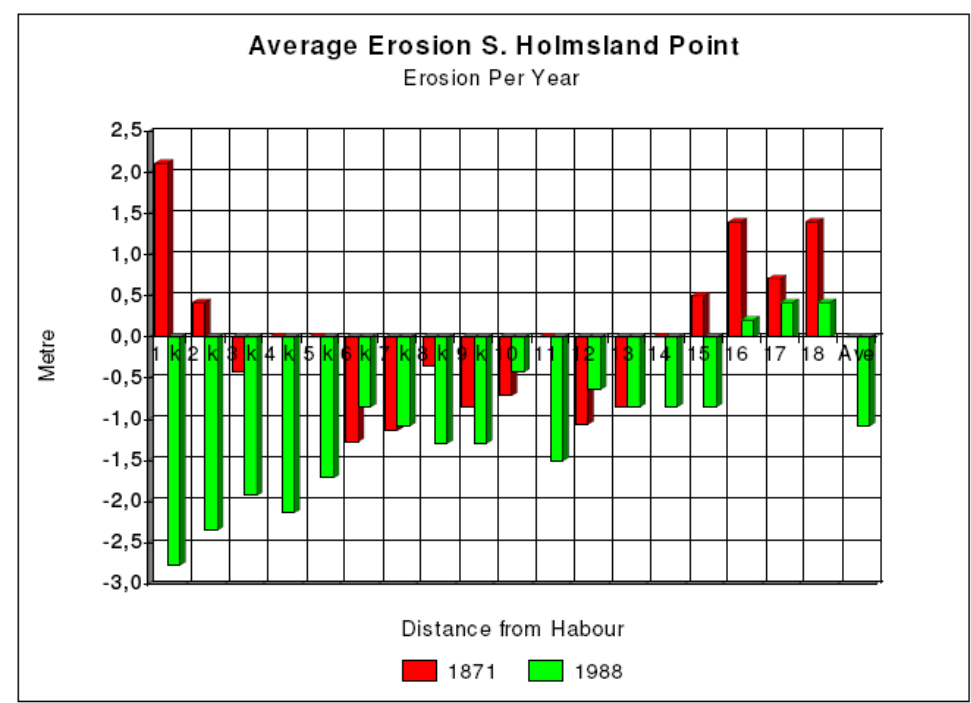

Fig. 4

As we see in fig. 4 the groin generates leeside erosion south of Hvide Sande Port. The values are not true because the groin is first placed in 1962 and the light grey shows the development from $1871-1988$.

The most interesting thing is we have accumulation $16 \mathrm{~km}$ south from the port over the last 200 years. This area is inside in reference area 3 in the project. 


\section{Sea Level}

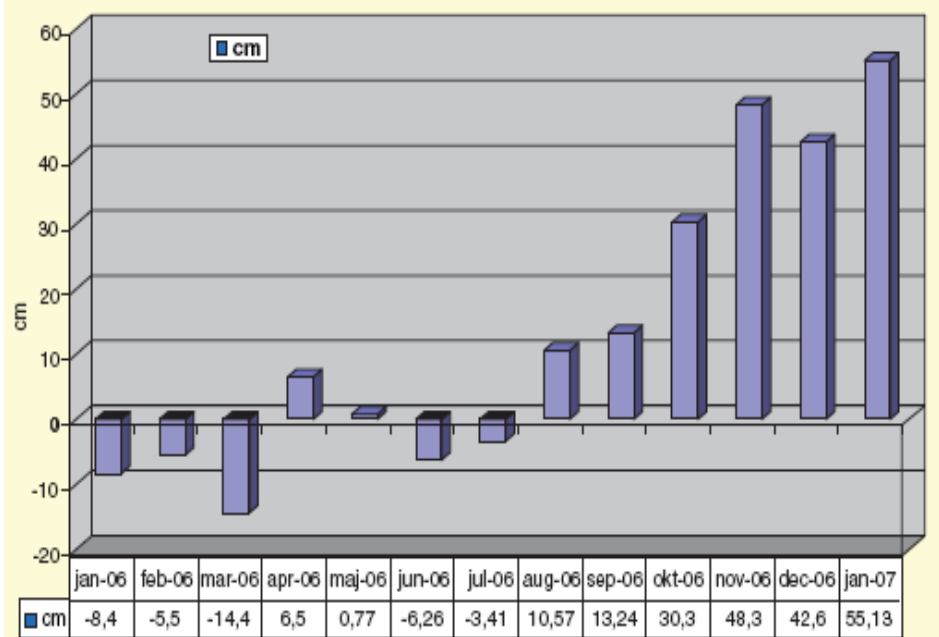

Fig. 5

The sea level was very high at the Danish west coast in the winter time 2006/07 The average sea level was $54 \mathrm{~cm}$ over DVR 90 in the period from 20 November 2006 to 20 January 2007.

\section{Wave Height}

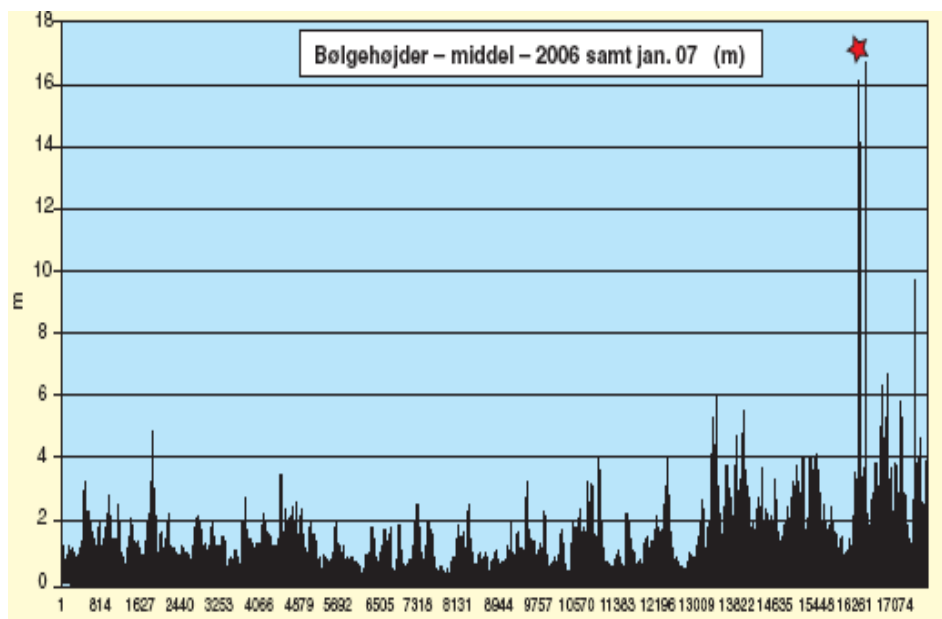

Fig 6

Fig 6 shows the wave height in 2006 and January 2007, where we have 5 heavy storms at the Danish west coast and 4 storms form 1. - 20. January 2007. 


\section{Design/Installation}

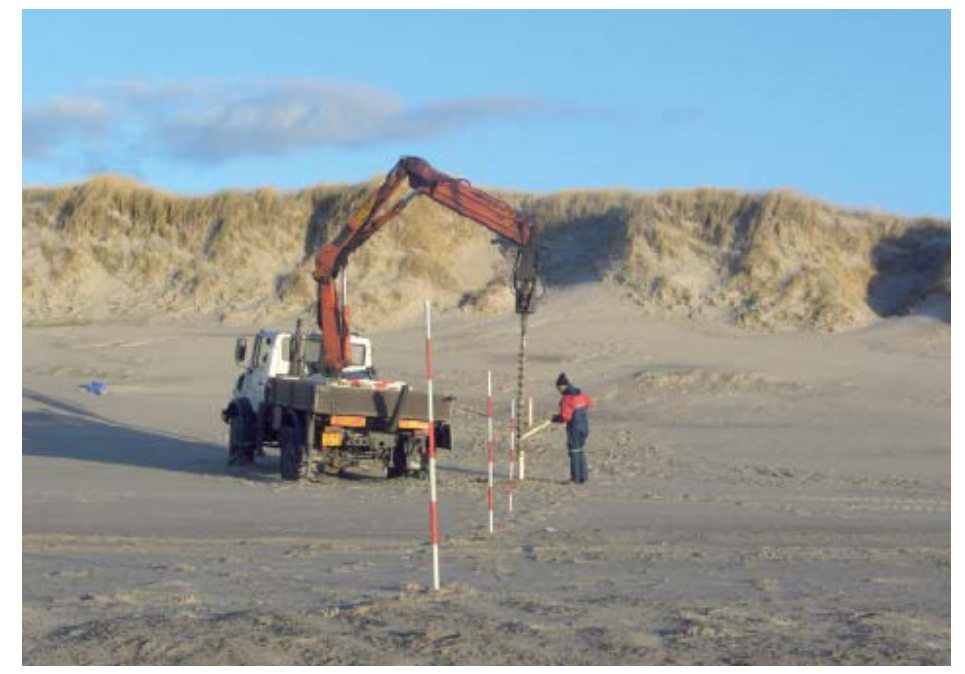

Fig. 7

The PEM modules are placed in a matrix along the coast line, with a distance at 100 meters between the rows and 10 meters in the cross.

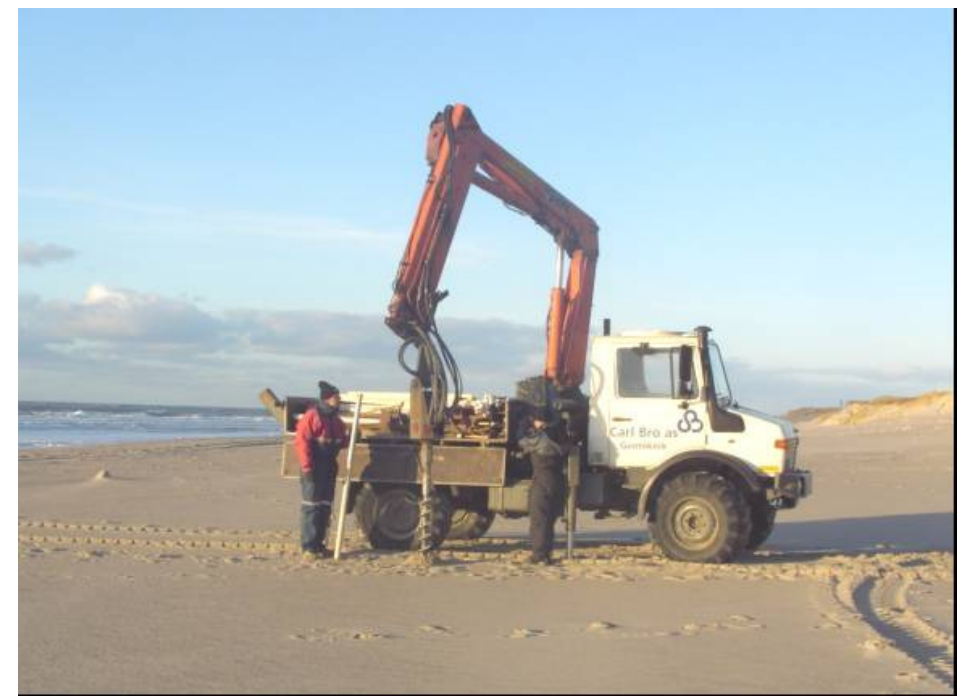

Fig. 8

The PEM modules are $175 \mathrm{~cm}$ long and are submerged $25 \mathrm{~cm}$ under the beach surface and are normally not visible at the beach. There are max 11 PEM modules in each row, because we don't like the beach wider than 100 meters. 


\section{Survey}

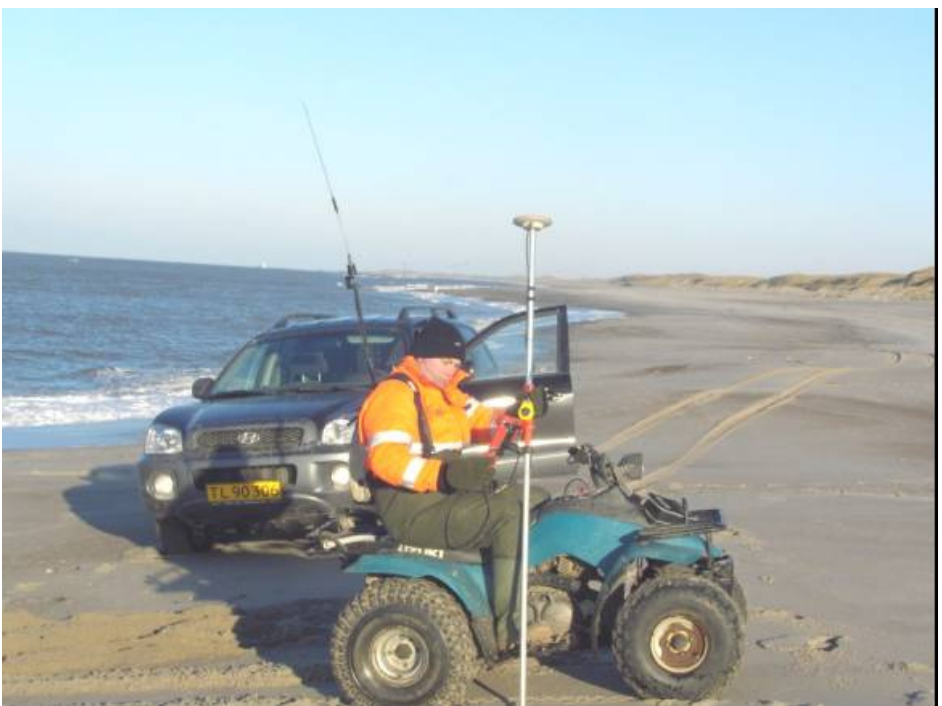

Fig. 9

The survey program is quarterly with 13 surveys over 3 years. There is 100 meters between the survey lines at the beach and the tolerance is below $2 \mathrm{~cm}$. The survey and data processing are done by Carl Bro A/S Denmark.

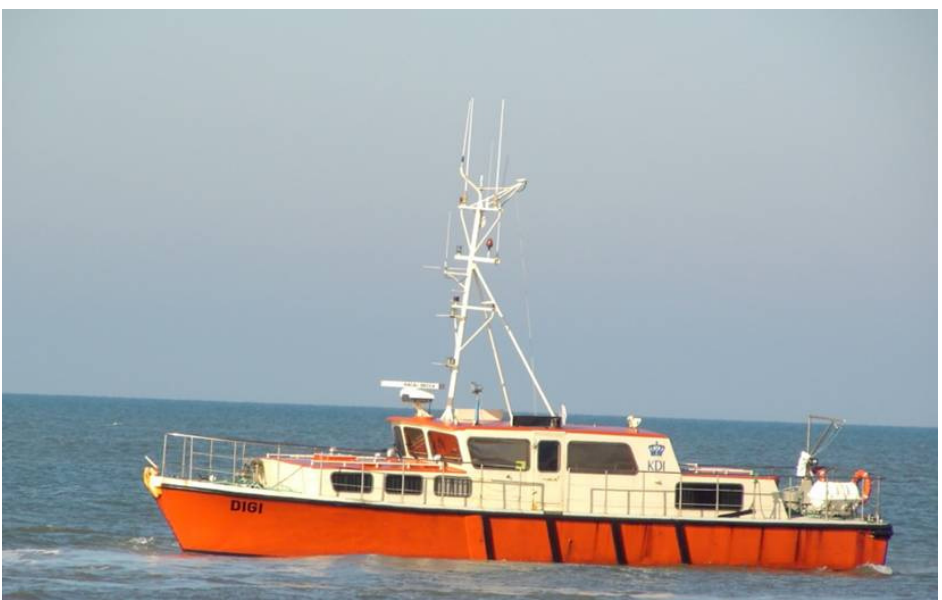

Fig 10

In the first year the sea survey was quarterly and half yearly in year 2 and 3 in the project period.

The distance between the survey lines along the coast line is 200 meters and 600 meters out in the sea. 


\section{Evaluation}

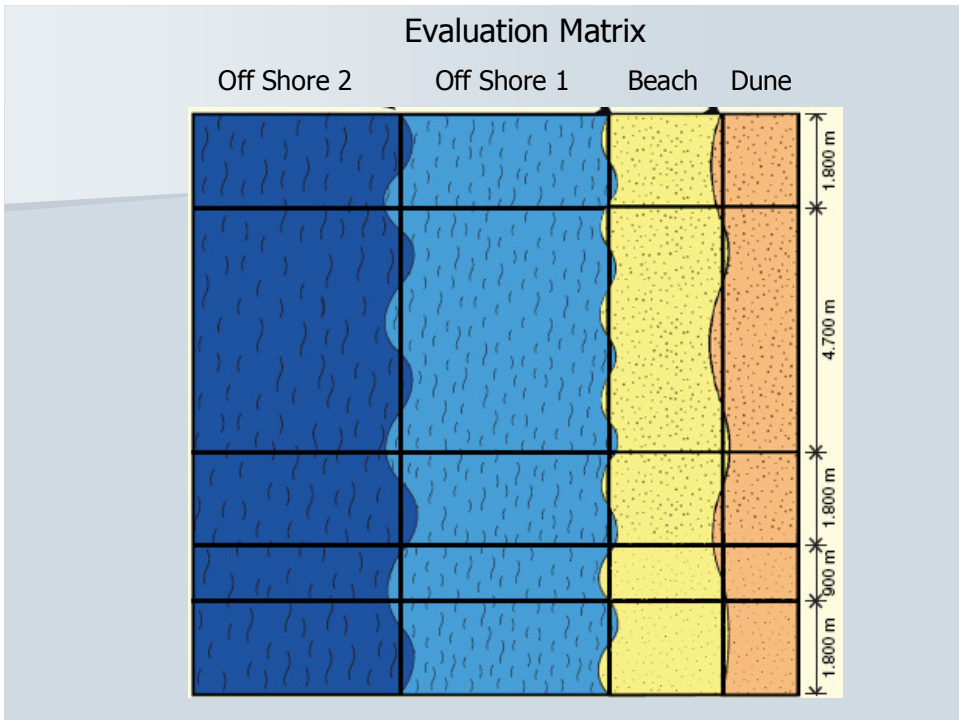

Fig 11

The evaluation is based at the dunes, average beach level (ABL) 100 meters wide from the dune foot (Fig. 12), and offshore 1 and 2 both 300 meters wide.

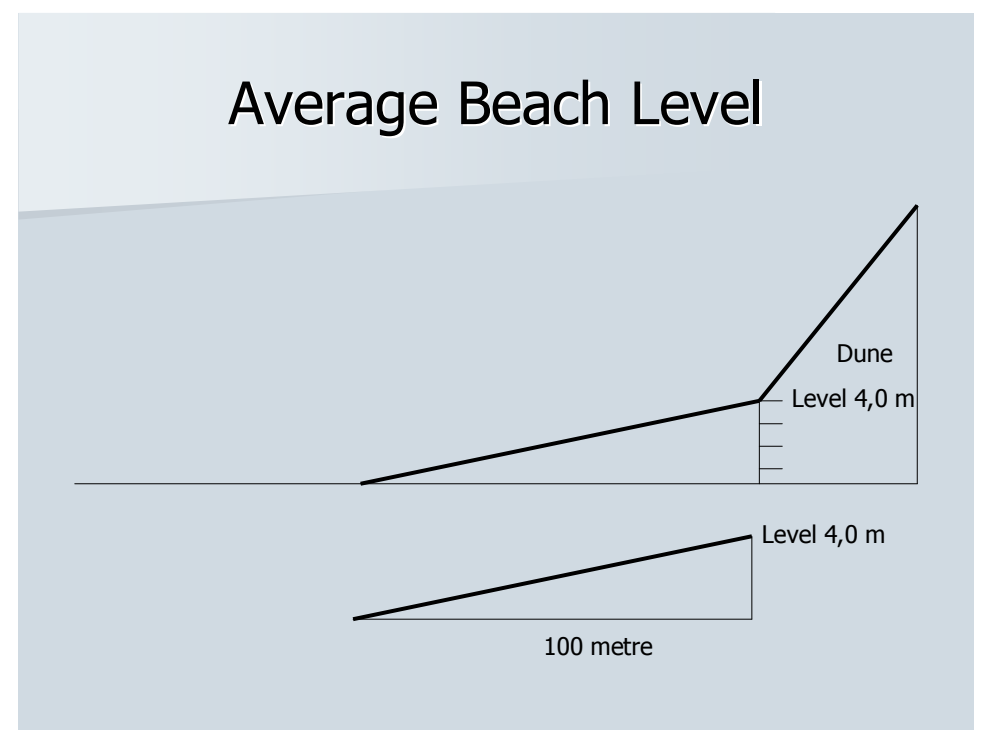

Fig 12

The ABL calculations are locked to the dune foot level $+4 \mathrm{~m}$ January 2005 . 


\section{Analysis - ABL}

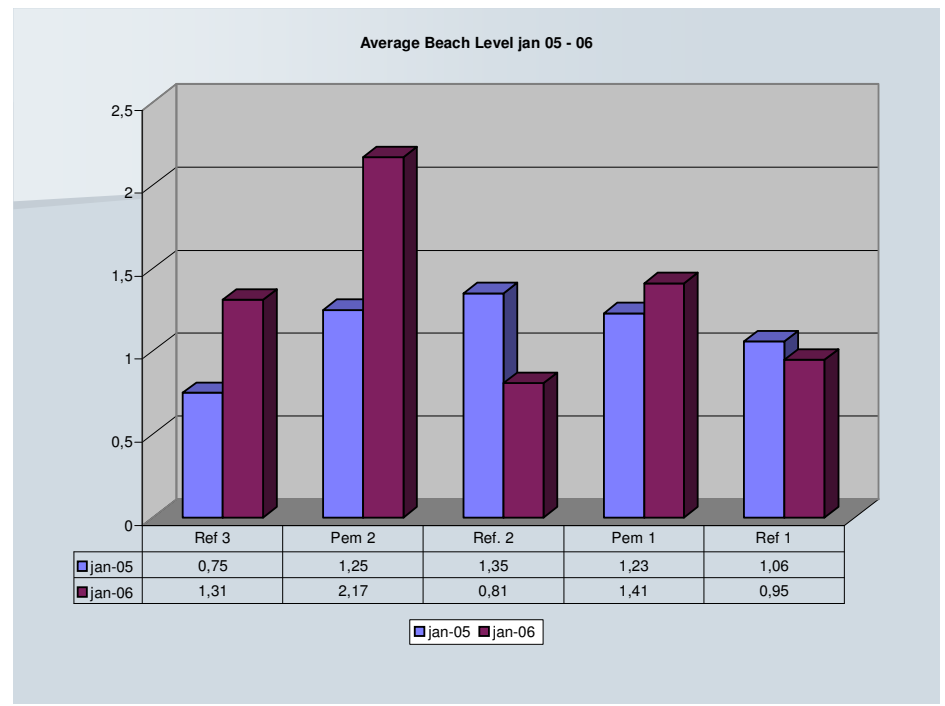

Fig. 13

Fig. 13 shows the average beach level by the project start January 2005 and January 2006 after the first year. Ref. 2 was the strongest area with ABL 1,35 m at project start.

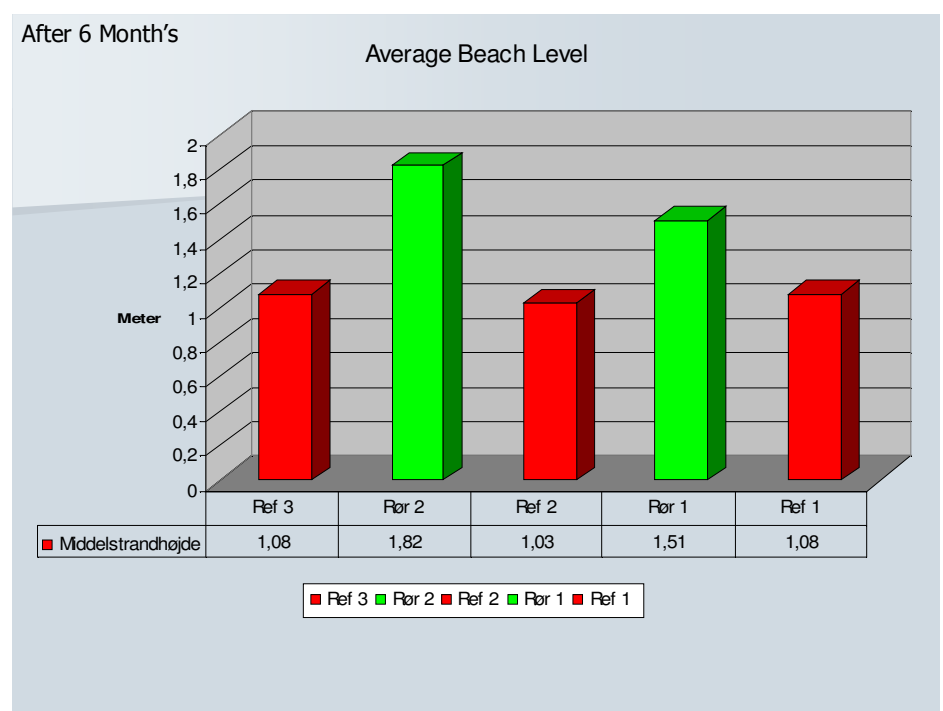

Fig. 14

Already after the first 6 month the results of the vertical drains was significant in relation to the reference areas. 


\section{Result ABL - 3 years}

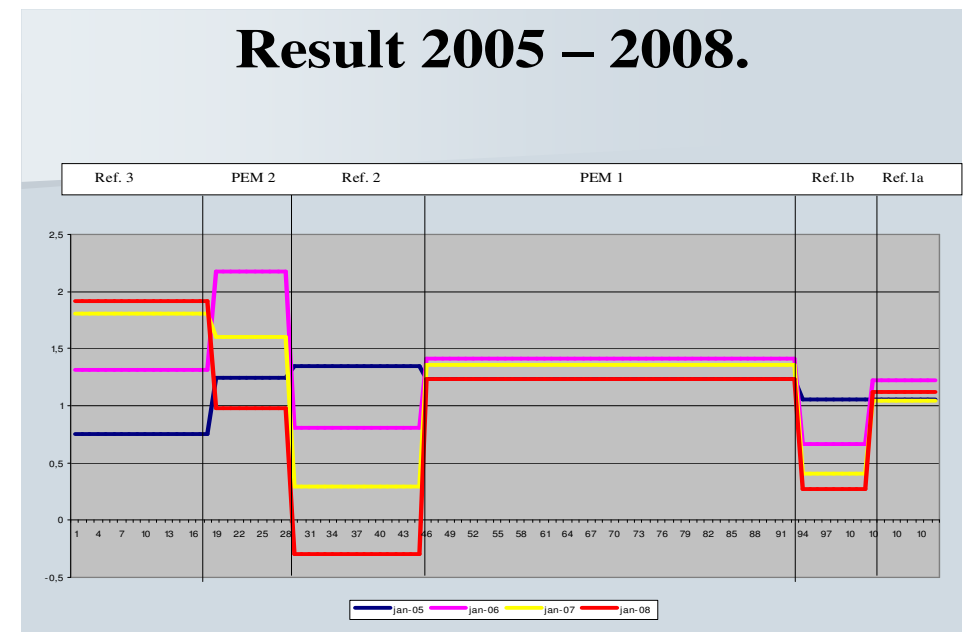

Fig 15

We see in fig. 15, there is a very significant and clear result after 3 years. The average beach level in PEM 1 is $157 \mathrm{~cm}$ higher in relation to ref. 2. The average beach level in PEM 2 is $137 \mathrm{~cm}$ higher in relation to ref 2.

We register during the first year that ref. 1 was disturbed with Bar Nourishment done of the Coastal Authorities in Denmark.(KDI)

\section{Dune foot development}

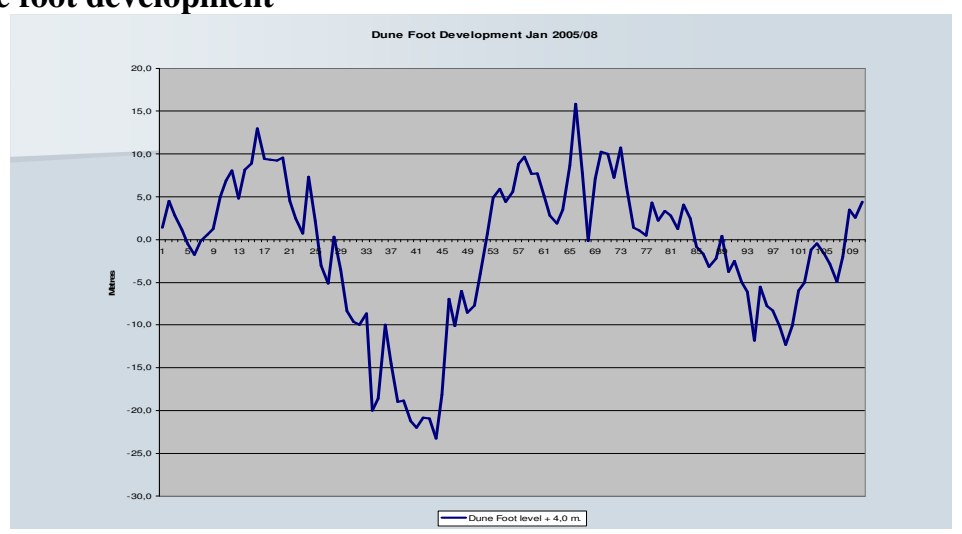

Fig. 16

We see in fig. 16 the dune foot move towards the shoreline in the drained areas, and big erosion in ref. $1 \mathrm{~b}$ and ref 2 . Ref 3 is an accumulation area over the last 200 years as we saw in Fig. 4. The average erosion in the dune foot in reference area 2 is 15,7 meters over 3 years. We think we would have seen the same situation in ref. 1, if this area not was disturbed with bar nourishment from KDI. 
Analysis.

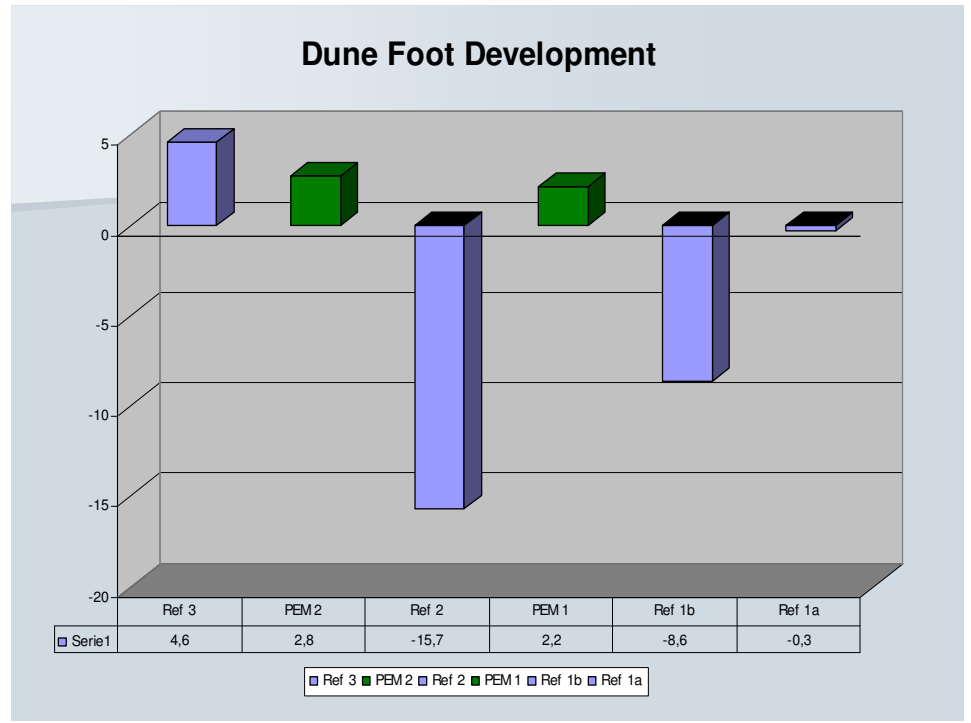

Fig. 17

After 3 years we see in fig 17 the dune foot moves towards the shoreline in the drained areas and ref. 3 , where we have leeside accumulation. In contrast we have big sea erosion in ref 2 and $1 \mathrm{~b}$.

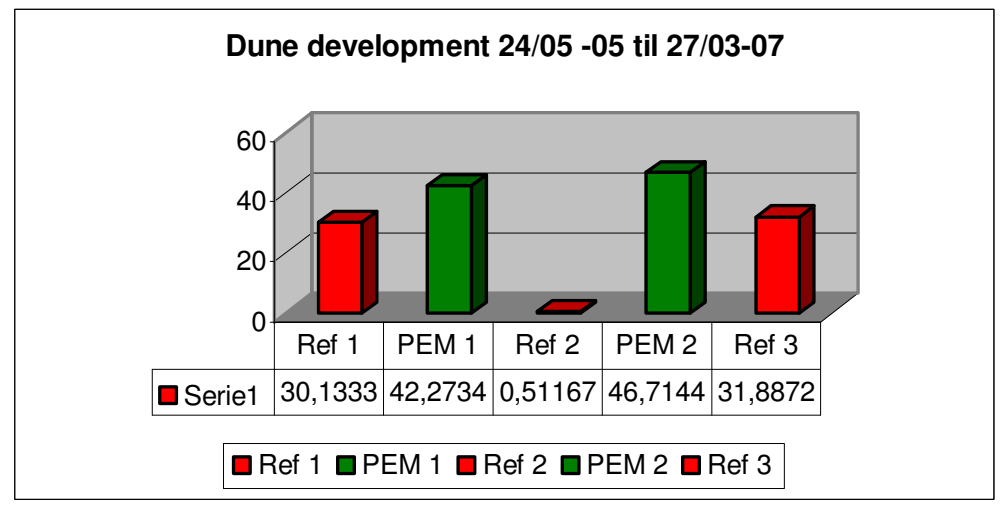

Fig. 18

We have a laser scan survey with airplane, as cover the area from the dune foot level 4 and 300 meters inside in the hinterland over 22 month.

The result is very significant. The sand drift to the hinterland is $50 \%$ higher from the drained areas in relation to ref. 1 and 3.

There is no accumulation in ref. 2, because we have big sea erosion in the dune front with a negative $\mathrm{ABL}$ at $-29 \mathrm{~cm}$ at the beach. 


\section{Drain Capacity.}

The main filter has a drain capacity at 150 I per minute equal to 9000 I per hour

10 filters has a drain capacity at 90.000 I per hour Over 6 hours the dain capacity is 540.000 litre

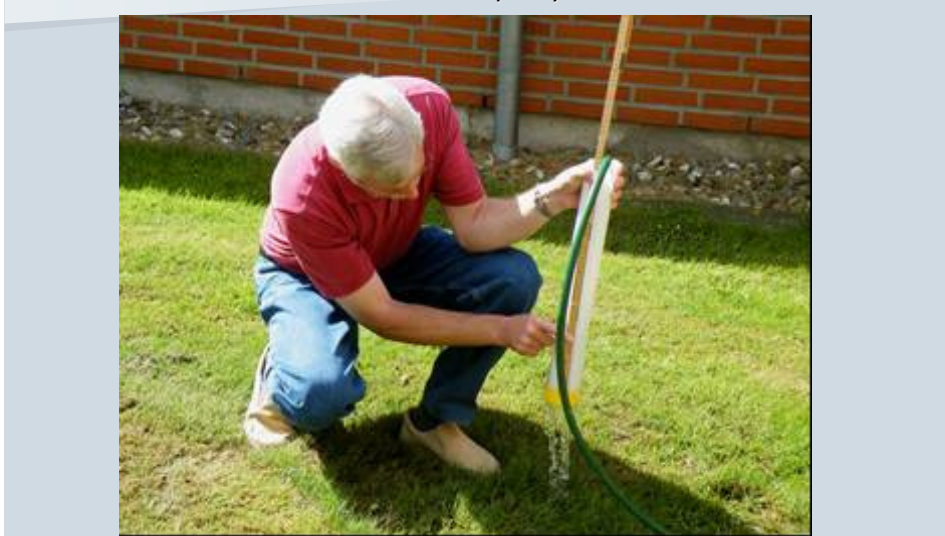

Fig. 19

The drain capacity at the main filter is tested by water flow with tap water. The test shows the main filter has a drain capacity at 1501 per minute.

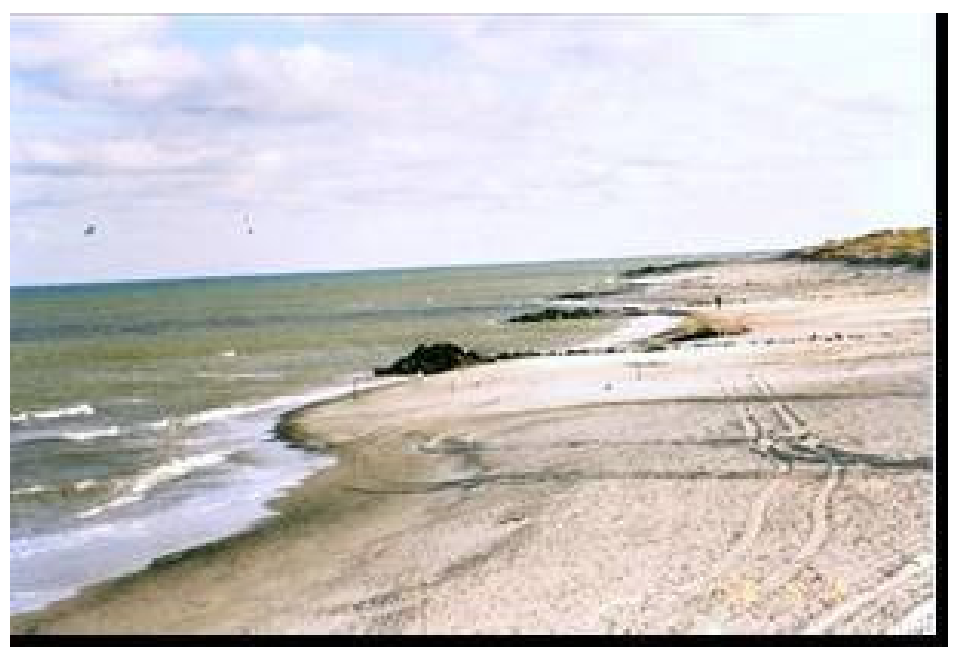

Fig 20

One row with vertical drain tubes Fig. 20 generates here a sand groin by Old Skagen in 1999. 


\section{Effect of the Drain tubes}

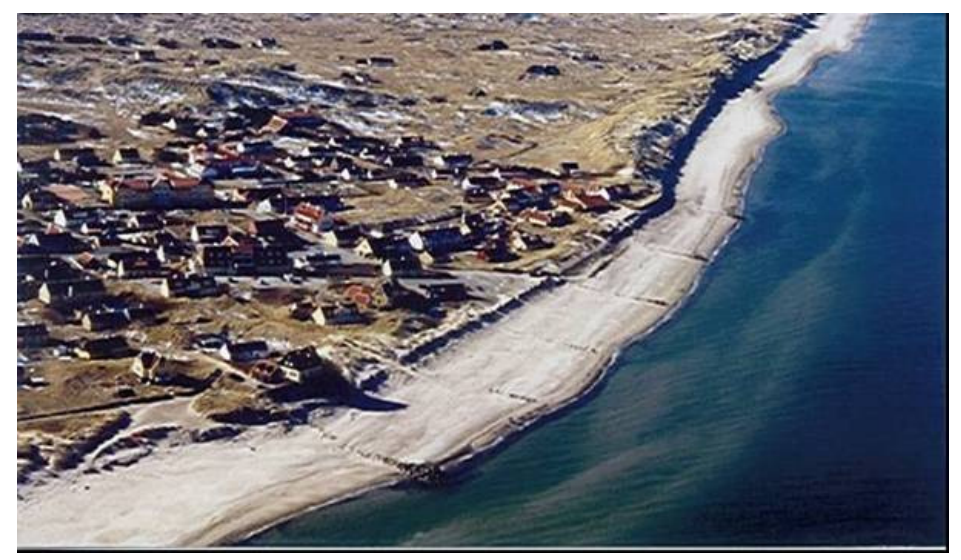

Fig. 21

Fig 21 is an Arial photo from year 2000 from old Skagen with drain tubes between the groins. We see clearly the sand groins between the old groins of stones as lay inside at the beach.

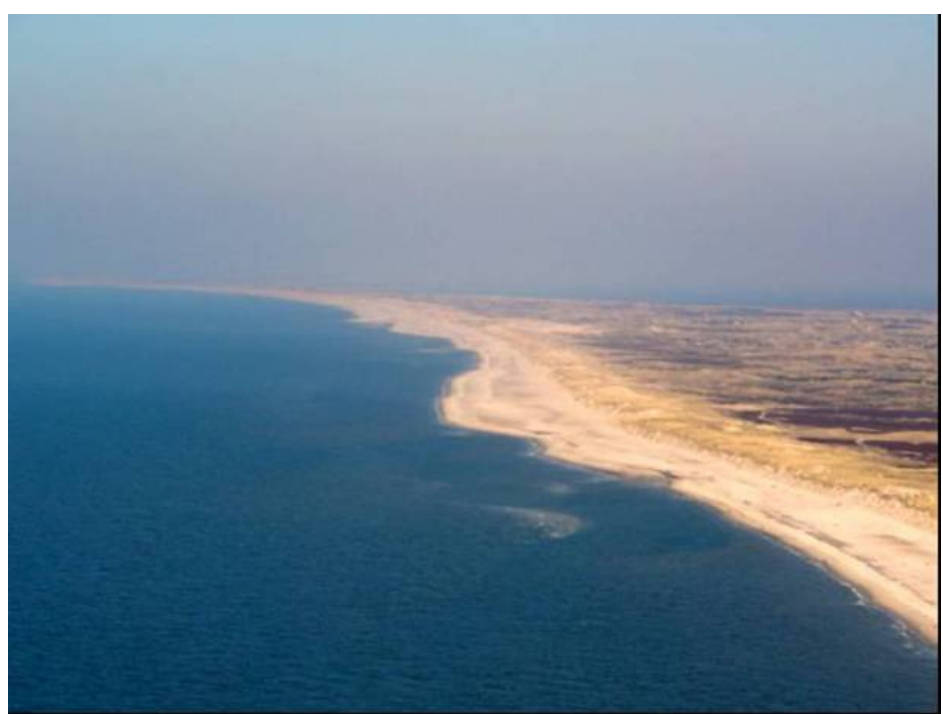

Fig. 22

In fig. 22 we see the effect of the drain tubes by Skodbjerge in the PEM area 2 after 6 month in July 2005. 


\section{Offshore development}

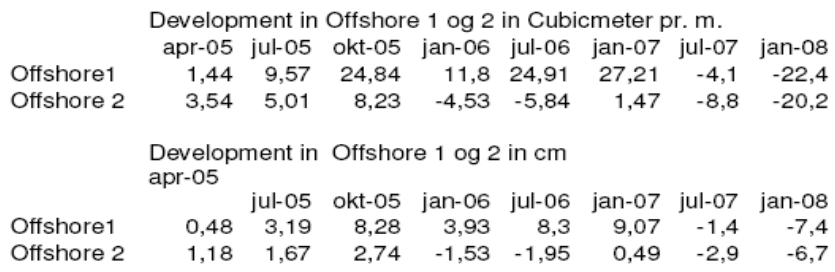

Detailed analysis shows a negative effect, at the southern end of the bar nourishment in off shore 1 and 2 . where the erosion in the sea bed is more than 300 cubic meters pr meter in ref $1 \mathrm{~b}$ off shore.

SIC has complained about bar nourishment inside the project to the Ministry of Transport who pay the project, but we made a mistake. We should have complained to the board for Scientific Dishonesty under the Ministry of Scientific.

\section{Conclusion}

1. The average beach level is significant higher in the drained areas in relation to ref. 1 and 2. The Beach in ref $1 \mathrm{~b}$ and ref 2 is eroded away over 3 years.

2. There is no leeside erosion, but leeside accumulation in ref. 3 .

3. The dune foot move towards the shoreline in the drained areas and ref 3 with leeside accumulation

4. The Dune accumulation is $50 \%$ higher in the drained areas in relation to ref 1 and 3.

5. The Sand comes from the long shore sediment transport at the coastline.

6. Vertical beach draining is a coastal protection solution in relation to the global sea level rise, because it raises the average beach level in front of the dunes.

\section{REFERENCES}

Jakobsen P. Pressure Equalisation Modules For Environmentally Friendly Coastal Protection, Yamba 2000 Australia.

Brøgger C. and Jakobsen P. Evaluation of the function of vertical drains, Conference ICS 2007 Gold Coast Australia.

Jakobsen P. and Brøgger C. Coastal protection based on Pressure Equalization Modules (PEM), Conference ICS 2007 Gold Coast Australia.

Brøgger C and Jakobsen P. Beach nourishment combined with SIC Vertical Drain System in Malaysia, Conference ICCE 2008 Hamburg.

Li L. and Barry D.A. Groundwater effects on Sediment transport: A modeling study of the mechanisms underlaying beachdewatering for erosion control, School of Civil and Environmental EngineeringThe University, Edingburgh.

\section{Acknowledgment}

We would like to thank the Board for Trafic, and Transport Minister Flemming Hansen as initiated this field test, and founded the project with 1,0 mill Euro. 
KEYWORDS - ICCE 2008

Environmentally Friendly Coastal Protection Based on Vertical Drains Authors: Poul Jakobsen and Claus Brøgger

Abstract number: 1159

Key words

Shore

Beach

Coast

Coastal

Erosion

Skagen

SIC

PEM

Pressure equalization modules

Beach Drain

Environmentally Friendly

Beach Dewatering

Vertical Drain 